\title{
Internalisasi Nilai-Nilai Dakwah Multikultural dalam Pembelajaran Al-Islam di Universitas Muhammadiyah Mataram
}

\author{
Sukarta \\ Program Studi Komunikasi Penyiaran Islam, Fakultas Agama Islam \\ Universitas Muhammadiyah Mataram,83115, Indonesia \\ nggihsilak@gmail.com
}

INFO ARTIKEL

Riwayat Artikel:

Diterima Desember 2017

Direvisi Januari 2018

Disetujui Februari 2018
ABSTRAKSI

Abstrak: Latar belakang dan perbedaan suku, budaya, ormas, paham keagamaan serta agama yang berbeda berpotensi menimbulkan konflik jika tidak terjadi saling memahami dan menghormati satu dengan yang lainnya apalagi tingkat heterogenitas dan pluralitas budaya yang sangat kompleks di Indonesia. Untuk itu penting sekali internalisasi nilai-nilai Dakwah multikultural dalam pembelajaran Al-Islam sebagai langkah preventif. Fokus penelitian ini adalah untuk membahas Internalisasi Nilai-nilai Dakwah Multikultural dalam Pembelajaran Al-Islam di Universitas Muhammadiyah Mataram. Dengan fokus penelitian mencakup: (1) Nilai-nilai Dakwah multikultural apa saja yang diinternalisasikan dalam pembelajaran Al-Islam di Universitas Muhammadiyah Mataram (2) Bagaimana proses internalisasi nilai-nilai Dakwah multikultural dalam pembelajaran Al-Islam di Universitas Muhammadiyah Mataram.

Pendekatan yang peneliti gunakan dalam penelitian ini adalah pendekatan kualitatif dan jenis penelitian yang digunakan adalah deskriptif atau dengan melakukan pendekatan deskriptif analitik, pengumpulan data dilakukan dengan tehnik wawancara, observasi dan dokumentasi.Tehnik analisa meliputi reduksi data, display data dan verifikasi data, pengecekan keabsahan temuan dilakukan dengan cara perpanjangan keikutsertaan penelitin, persistent observation (ketekunan Pengamatan) dan triangulasi. Sumber informan peneliti adalah dosen Al-Islam Universitas Muhammadiyah Mataram, dekan FKIP UMM, ketua lembaga pengkajian dan pengamalan Islam (LP2I) UMM, mahasiswa. Hasil dalam penelitian ini adalah: (1) Nilai-nilai yang diinternalisasikan dalam pembelajaran Al-Islam adalah nilai Ilahiyah dan nilai Insaniyah. Nilai ilahiyah ditekankan kepada mahasiswa yang multikultural homogen atau seagama namun berbeda ormas, suku dan budaya adapun nilai insaniyah ditekankan kepada multikultural beda agama. (2) Proses internalisasi nilai-nilai Dakwah multikultural dalam pembelajaran Al-Islam di UMM terwujud dalam bentuk beberapa kegiatan keislaman baik di dalam kelas maupun di luar kelas seperti: pembelajaran Al-Islam di dalam kelas, shalat dzuhur berjamaah di masjid kampus dan dilanjutkan dengan siraman rohani atau kultum, sertifikasi baca Al-Quran, Tausiyah berupa Imtaq setiap sabtu pagi, shalat jumat di masjid. Proses tersebut dilakukan dalam beberapa strategi yaitu melakukan perencanaan progam kegiatan, melakukan kerjasama dengan organisasai kemahasiswaan seperti Ikatan Mahasiswa Muhammadiyah, memberikan teladan kepada mahasiswa, melakukan pendekatan kepada mahasiswa, dan strategi memanfaatkan kebijakan pimpinan. Hasilnya adalah mahasiswa bisa saling bertoleransi dalam perbedaan dan terwujud suasana yang kondusif dan aman. 
Kata Kunci:

Internalisasi,

Nilai-nilai Pendidikan,

Pendidikan Multikultural

Al-Islam

Univeritas Muhammadiyah Mataram

Keywords:

Internalization,

Educations Values,

Multicultural Education,

Al-Islam Study,

Muhammadiyah Mataram University
Abstract : Background and differences of ethnicity, culture, mass organizations, different religions and religious ideals have potentials to cause conflict if it does not create mutual understanding and respect for each other, especially the level of heterogeneity and cultural plurality that is very conflex in Indonesia. Therefore, it is pretty important to internalize the values of multicultural da'wah in Al-Islam learning as a preventive measure. The focus of this research is to discuss the Internalization of Multicultural Da'wah Values in Al-Islam Learning at Muhammadiyah University of Mataram. With the focus of research include: (1) What multicultural values of da'wah are internalized in Al-Islam learning at Muhammadiyah University of Mataram (2) How is the process of internalizing the values of multicultural da'wah in Al-Islam learning at Muhammadiyah University of Mataram.

The approach used by this research is qualitative approach and the type of research used is descriptive or by analytical descriptive approach, data collection is done by interview technique, observation and documentation. Analysis techniques include data reduction, data display and data verification, checking the validity of the findings carried out by extending the participation of research, persistent observation and triangulation. Sources of research informant is lecturer of Al-Islam Muhammadiyah University of Mataram, Dean of FKIP UMM, Head of Islamic study and practice (LP2I) UMM, students. The results of this study are: (1) the values internalized in Al-Islam learning are Illahiyah values and Insaniyah values. Ilahiyah value is emphasized to students who are multicultural homogeneous or religious but in different mass organizations, tribes and cultures while the value of insaniyah is emphasized to multicultural religions. (2) The process of internalization of multicultural da'wah values in the learning of Al-Islam in UMM is manifested in the form of some Islamic activities both in class and outside the class such as: AlIslam learning in the classroom, dzuhur praying in the campus Mosque and continued with splash of spiritual or seven minutes speech (kultum), certification of reading Al-Quran, Tausiyah in the form of Imtaq every Saturday morning, prayer Friday at the Mosque. The process is carried out in several strategies, ie planning activities program, collaborating with student organizations such as Muhammadiyah Student Association, providing examples to students, approaching students, and strategies to utilize leadership policies. The result is that students can tolerate each other in a different way and create a conducive and safe environment.

\section{Pendahuluan}

Pendidikan dan dakwah merupakan kunci kemajuan suatu bangsa. Suatu bangsa dikatakan maju jika memiliki sumber daya manusia yang handal dan bermutu, semua ini tentu diperoleh melalui pendidikan dan dakwah yang berkualitas. Pendidikan dan dakwah merupakan sarana untuk memajukan peradaban, mengembangkan masyarakat, dan membuat generasi mampu berbuat banyak bagi kebaikan umat manusia.Dalam pandangan ajaran Islam, "segala sesuatu harus dilakukan secara rapi, benar, tertip, dan teratur. Proses harus diikuti dengan baik dan semua tidak boleh dilakukan secara asal-asalan."

Universitas Muhammadiyah Mataram memiliki mahasiswa dan civitas akademika dengan heterogenitas suku, etnis, dan berbagai macam latar belakang yang berbeda-beda seperti civitas akademika dan mahasiswa yang berasal dari bima, dompu, sumbawa, flores dan lombok. Keragaman suku tersebut setelah diinternalisasikan nilai-nilai pendidikan multikultural melalui pembelajaran Al-Islam untuk bisa saling menghargai dan menghormati maka semua aman dan damai di Universitas Muhammadiyah Mataram.

${ }^{1}$ Didin Hafiduin dan Hendri Tanjung, Manajemen syari'at dalam peraktek (Jakarta: Gema Insani, 2003$), 1$. 
Fenomena tersebut sangat menarik untuk diteliti bagaimana pendidikan di Universitas Muhammadiyah Mataram mampu menjembatani melalui tekstual mata kuliah al-Islam dengan realitas mahasiswa yang berasal dari budaya dan suku yang beragam. Sebuah fakta multikultural di Universitas Muhammadiyah Mataram akan memberikan sebuah telaah; pertama, tentang konsep pembelajaran yang diberikan kepada mahasiswa Universitas Muhammadiyah Mataram akan berlainan dengan konsep pembelajaran di perguruan tinggi lain yang tidak memiliki latar belakang Multikultural. Kedua adalah kemampuan UMM membuat suasana kondusif dan damai meskipun latar belakang mahasiswanya berbeda suku ada yang berasal dari bima, dompu, flores, Lombok dll. Namun tetap aman dan damai.

Realita dan fakta yang menarik di Universitas Muhammadiyah Mataram adalah civitas akademika dan mahasiswanya yang multikultural yang terdiri dari etnis sasak, etnis samawa, etnis mbojo dan etnis jawa. Selain itu, dalam satu kelas terdapat mahasiswa yang berasal dari NTT, Sumbawa, Flores, Bima, Dompu dan Jawa dan juga terdapat mahasiswa yang beragama Islam, kresten, hindu. Sebagai contoh dalam satu kelas di prodi geografi FKIP UMM mahasiswa keseluruhan berjumlah 40 orang, 1 orang beragama kresten yaitu Simon Litinau NIM.11214A0067, 1 orang beragama hindu yaitu Sabina Vebronia Dhiu NIM.11214A0135, dari 40 mahasiswa dalam satu kelas yang berbeda agama hanyalah 2 orang mahasiswa sedangkan sisanya yang berjumlah 38 semuanya beragama islam namun berasal dari paham dan latar belakang yang berbeda-beda dan yang menarik dalam observasi peneliti adalah meskipun terdapat mahasiswa yang beragama hindu dan kresten semuanya tetap mengikuti mata kuliah al-Islam. dari hasil observasi dan dokumentasi diatas dapat disimpulkan bahwa mayoritas dalam satu kelas adalah multikultural homogen berbeda latar belakang namun tetap seagama yaitu agama islam sedangkan multikultural heterogen berbeda agama jumlahnya sedikit atau minoritas namun dalam pengamatan peneliti tetap aman dan kondusif dalam proses belajar mengajar mata kuliah Al-Islam di dalam kelas. ${ }^{2}$

Keberagaman latar belakang budaya dan suku di Universitas Muhammadiyah Mataram berpotensi mempengaruhi karakter dalam pembelajaran sebagai contoh dalam pembahasan materi munakahat, suku sasak melakukan perkawinan dengan cara merarik maling yang tidak sesuai dengan tuntunan Rasulullah shallallahu alaihi wa sallam, sedangkan suku Mbojo perkawinan dengan cara khitbah atau dipinang adapun tradisi di Flores mengadakan acara yasinan dan tahlilan dalam acara pernikahan sedangkan dalam pedoman al-Islam menilai prosesi merarik maling kemudian menikah dengan mengadakan yasinan dan tahlilan tersebut tidak sesuai dengan tuntunan Rasulullah shallallahu 'alaihi wa sallam. Namun perbedaan tersebut ditanggapi oleh mahasiswa dengan aman dan tidak menimbulkan konflik serta terjalin hubungan yang harmonis, saling menghargai dan memahami serta memaklumi latar belakang yang berbeda padahal pada umumnya perbedaan budaya dan paham keagamaan sering menimbulkan konflik. Oleh sebab itu dan berangkat dari latar belakang tersebut, maka peneliti terinspirasi dan termotivasi untuk melakukan penelitian tentang: Internalisasi Nilai-nilai Pendidikan Multikultural dalam Pembelajaran Al-Islam di Universitas Muhammadiyah Mataram.

Urgensi dari Penelitian ini adalah menjadi bagian dari khazanah pemikiran pendidikan dalam perspektif Pendidikan Multikultural pada pendidikan Islam. Sehingga temuan dari penelitian ini nantinya akan dapat melengkapi teori-teori pengembangan pendidikan berbasis Multikultural. Selain itu, pentingnya pendidikan berbasis Multikultural akan dapat dijadikan pijakan dan pertimbangan bagi pembuat kebijakan dalam mengambil kebijakan tentang pengembangan lembaga pendidikan berbasis Multikultural dalam menghadapi heterogenitas budaya, tradisi, etnis, ormas dan agama yang sebelumnya berwawasan sempit menjadi luas

Identifikasi dan Batasan Masalah dari Penelitian ini adalah Penulis menyadari akan luasnya lingkup penelitian, sehingga dibatasi dalam lingkup (a) Perbedaan suku, budaya, dan agama

\footnotetext{
${ }^{2}$ Hasil Observasi dan Pengisian Angket dengan Mahasiswa Aktip, Mata Kuliah Al-Islam, di Universitas Muhammadiyah Mataram pada Fakultas Keguruan dan Ilmu Pengetahuan Prodi Pendidikan Geografi, Tanggal 10 Juni 2014.
} 
mahasiswa di Universitas Muhammadiyah Mataram merupakan fenomena dalam proses pembelajaran khususnya mata kuliah Al-Islam (b) Perbedaan suku, budaya, dan agama mahasiswa di Universitas Muhammadiyah Mataram terjalin dengan aman dan damai (c) Nilainilai dakwah multikultural dalam pembelajaran Al-Islam di Universitas Muhammadiyah Mataram (d) Proses internalisasi nilai-nilai dakwahmultikultural dalam pembelajaran Al-Islam di Universitas Muhammadiyah Mataram

Berdasarkan permasalahan yang telah teridentifikasi di atas, maka batasan masalah dalam penelitian ini meliputi : (a) Nilai-nilai dakwah multikultural yang diinternalisasikan dalam pembelajaran Al-Islam di Universitas MuhammadiyahMataram?(b) Proses internalisasi nilai-nilai dakwah multikultural dalam pembelajaran Al-Islam di Universitas Muhammadiyah Mataram?

Sedangkan batasan masalah di atas, maka rumusan masalah dalam penelitian ini meliputi (a) Apakah Nilai-nilai dakwah multikulturalyang diinternalisasikan dalam pembelajaran Al-Islam di Universitas Muhammadiyah Mataram? (b) Bagaimana proses internalisasi nilai-nilai dakwah multikultural dalam pembelajaran Al-Islam di Universitas Muhammadiyah Mataram?

Adapun Tujuan Penelitian ini adalah (a) Mengetahui nilai-nilai dakwah multikultural dalam pembelajaran Al-Islam di Universitas Muhammadiyah Mataram (b) Mengungkap proses internalisasi nilai-nilai dakwah multikultural dalam pembelajaran Al-Islam di Universitas Muhammadiyah Mataram

\section{Kajian Teoritik}

\section{A. Tinjauan Tentang Internalisasi Nilai-Nilai Dakwah Multikultural}

Secara etimologis, internalisasi menunjukkan suatu proses. Dalam kaidah bahasa Indonesia akhiran 'isasi' mempunyai definisi proses. Sehingga internalisasi dapat didefinisikan sebagai suatu proses. Dalam kamus besar bahasa Indonesia internalisasi diartikan sebagai penghayatan, pendalaman, penguasaan secara mendalam yang berlangsung melalui binaan, bimbingan dan sebagainya $^{3}$

Jadi teknik pembinaan agama Islam yang dilakukan melalui internalisasi adalah pembinaan yang mendalam dan menghayati nilai-nilai relegius (agama Islam) yang dipadukan dengan nilainiali pendidikan secara utuh yang sasarannya menyatu dalam kepribadian peserta didik, sehingga menjadi satu karakter atau watak peserta didik.

Dalam kerangka psikologis, internalisasi diartikan sebagai penggabungan atau penyatuan sikap, standart tingkah laku, pendapat dan seterusnya di dalam kepribadian.Freud yakin bahwa superego, atau aspek moral kepribadian berasal dari internalisasi sikap-sikap parental (orang tua). ${ }^{4}$

Dalam proses internalisasi yang dikaitkan dengan pembinaan peserta didik atau anak asuh ada tiga tahap yang mewakili proses atau tahap terjadinya internalisasi: ${ }^{5}$

a). Tahap Transformasi Nilai : Tahap ini merupakan suatu proses yang dilakukan oleh pendidik dalam menginformasikan nilai-nilai yang baik dan kurang baik. Pada tahap ini hanya terjadi komunikasi verbal antara pendidik dan peserta didik atau anak asuh

b). Tahap Transaksi Nilai : Suatu tahap pendidikan nilai dengan jalan melakukan komunikasi dua arah, atau interaksi antara peserta didik dengan pendidik yang bersifat interaksi timbal-balik.

c). Tahap Transinternalisasi : Tahap ini jauh lebih mendalam dari tahap transaksi. Pada tahap ini bukan hanya dilakukan dengan komunikasi verbal tapi juga sikap mental dan kepribadian.Jadi pada tahap ini komunikasi kepribadian yang berperan secara aktif.

\footnotetext{
${ }^{3}$ DEPDIKBUD, Kamus Besar Bahasa Indonesia (Jakarta: Balai Pustaka, 1989), 336.

${ }^{4}$ Chaplin, Kamus Lengkap Psikologi (Jakarta: PT Raja Grafindo Persada, 1993), 256.

${ }^{5}$ Muhaimin, Srategi Belajar Mengajar (Surabaya: Citra Media, 1996), 153.
} 


\section{B. Tinjauan Tentang Pendidikan Multikultural}

Mundzier Suparta ${ }^{6}$ dalam bukunya Islamic Multicultural Education, mencatat lebih dari sepuluh definisi tentang pendidikan multikultural, diantaranya adalah; (a) Pendidikan Multikultural adalah sebuah filosofi yang menekankan pada makna penting, legitimasi dan vitalitas keragaman etnik dan budaya dalam membentuk kehidupan individu, kelompok maupun bangsa. (b) Pendidikan Multikultural adalah menginstitusionalkan sebuah filosofi pluralisme budaya ke dalam system pendidikan yang didasarkan pada prinsip-prinsip persamaan (equality), saling menghormati dan menerima, memahami dan adanya komitmen moral untuk sebuah keadilan sosial. (c) Pendidikan Multikultural adalah sebuah pendekatan pengajaran dan pembelajaran yang didasarkan atas nilai-nilai demokratis yang mendorong berkembangnya pluralisme budaya; dalam hampir seluruh bentuk komprehensifnya.Pendidikan multikultural merupakan sebuah komitmen untuk meraih persamaan pendidikan, mengembangkan kurikulum yang menumbuhkan pemahaman tentang kelompok-kelompok etnik dan memberangus praktikpraktek penindasan.(d) Pendidikan Multikultural merupakan reformasi sekolah yang komprehensif dan pendidikan dasar untuk semua anak didik yang menentang semua bentuk diskriminasi dan intruksi yang menindas dan hubungan antar personal di dalam kelas dan memberikan prinsip-prinsip demokratis keadilan sosial.

\section{Tinjauan tentang Pembelajaran Al-Islam}

Istilah pembelajaran adalah proses interaksi peserta didik dengan pendidik dan sumber belajar pada suatu lingkungan belajar. ${ }^{7}$

Yang dimaksud Al-Islam dalam konteks penelitian ini adalah mata kuliah Al-Islam yang diajarkan di Universitas Muhammadiyah Mataram yang mencakup Al-Islam; 1) yaitu pembahasan tentang akidah yang diajarkan pada semester pertama, Al-Islam. 2)yaitu pembahasan tentang ibadah yang diajarkan pada semester kedua dan Al-Islam 3) yaitu materi Akhlaq yang diajarkan pada semester ketiga. ${ }^{8}$

\section{Pembahasan}

\section{A. Nilai-Nilai Dakwah Multikultural Yang Diinternalisasikan Dalam Pembelajaran Al-Islam di Universitas Muhammadiyah Mataram}

Berdasarkan temuan peneliti saat dilapangan mengenai nilai-nilai pendidikan multikultural yang diinternalisasikan dalam pembelajaran Al-Islam adalah menanamkan nilai ilāhiyahdan nilai Insāniyah yang ditanamkan pada mahasiswa di Universitas Muhammadiyah Mataram. Peneliti temukan melalui observasi lapangan dan wawancara dengan beberapa informan yang dianggap kompeten dalam memamparkan tentang kondisi mahasiswa yang mengarah pada pembentukan religius culture.

Sebagaiman hasil wawancara diatas bahwa salah satu nilai pendidikan multikultural yang diinternalisasikan dalam pembelajaran Al-Islam di Universitas Muhammadiyah Mataram adalah nilai ilahiyah. Internalisasi nilai-nilai Ilāhiyah yang tertanam dalam jiwa mahasiswa akan membuat mahasiswa selalu merasa bahwa Allah melihat dan mengawasi semua perbuatan dan tingkah lakunya, sehingga dengan terbiasanya dengan sikap tersebut secara bertahap mereka menjadi terbiasa, dan akibat terbiasa tersebut akan menjadi karakter dan menjadi seorang muslim yang memiliki akidah yang kuat.

\footnotetext{
${ }^{6}$ Mundzier Suparta, Islamic Multicultural Education: Sebuah Refleksi Atas Pendidikan Agama Islam Di Indonesia (Jakarta: Al Ghazali Center, 2008), 34-37.

${ }^{7}$ Tim Penyusun UURI. Undang-Undang Republik Indonesia Nomor 14 Tahun 2005 Tentang Guru dan Dosen (Bandung: Citra Umbara, 2006), 74

${ }^{8}$ Lembaga Pengkajian dan Pengamalan Islam Universitas Muhammadiyah Mataram, Pedoman Buku Ajar Al-Islam(Mataram: LP2I, 2013), 9 .
} 


\section{B. Nilai Ilāhiyah}

Temuan peneliti mengenai nilai ilāhiyah yang ditanamkan di Universitas Muhammadiyah Mataram adalah sebagai berikut: a). bahwa ada kewajiban bagi mahasiswa sejak menjadi mahasiswa baru untuk mengikuti rangkaian-rangkaian kegiatan internalisasi nilai ilāhiyah baik secara formal maupun nonformal. b). penanaman nilai Ilāhiyah benar-benar dilaksanakan di Universitas Muhammadiyah Mataram. c). nilai yang di utamakan untuk di internalisasikan kepada mahasiswa yang multukultural homogen atau berbeda ormas dan paham keagamaan namun seagama yaitu agama Islam adalah nilai Ilāhiyah atau nilai Akidah yang tertuang padamata kuliah Al-Islam 1 semester pertama d). penanaman nilai Ilāhiyah dilakukan melalui kegiatan formal dengan belajar Al-Islam 1 di dalam kelas dan nonformal berupa kegiatan-kegiatan keislaman di luar kelas seperti mengikuti kegiatan IMTAQ dan Kultum. e). Nilai Ilāhiyah yang ditanamkan di Universitas Muhammadiyah Mataram adalah nilai Keimanan, Ketakwaan, Islam, Ikhsan, Ikhlas, Syukur, Tawakal, dan Sabar.

\section{Nilai Insāniyah}

Diantara nilai dalam pendidikan multikultural yang diinternalisasikan dalam pembelajaran AlIslam di Universitas Muhammadiyah Mataram adalah nilai Insāniyah, Nilai-nilai Insāniyah merupakan nilai kemanusiaan atau moralitas dan Akhlaq antara sesama manusia, hal tersebut sangat penting untuk di internalisasikan dalam dunia pendidikan, karena dengan nilai Insāniyah ini diharapkan mampu menciptakan suasana saling menghargai dan menghormati serta toleran meskipun berbeda paham dan berbeda agama antara mahasiswa.Nilai karakter religius berupa nilai Insāniyah tersebut diharapkan dapat menjadi agen of change ditengah kemrosotan moral dan spiritual manusia saat ini, karakter religius berupa nilai Insāniyahdiharapkan dapat menjadi benteng mahasiswa Universitas Muhammadiyah Mataram dari arus globalisasi yang melanda dunia dan Indonesia saat ini.

Temuan peneliti mengenai nilai Insāniyah ini adalah: a). manusia adalah makluk sosial, b). internalisasi nilai multikultural dalam pembelajaran Al-Islam yaitu nilai Insāniyah yang dilakukan melalui pelajaran Al-Islam 3 tentang Akhlaq di dalam kelas dan kegiatan-kegiatan Lembaga Pengkajian dan Pengamalan Islam (LP2I) di luar kelas, c). penanaman nilai Insāniyah melalui jalur formal yaitu mahasiswa wajib mengikuti mata kuliah Al-Islam 3 di dalam kelas dan nonformal yaitu kegiatan-kegiatan di luar kelas seperti mendaki gunung bersama mahasiswa yang berbeda agama untuk membangun kebersamaan serta penggalangan dana untuk korban bencana alam oleh mahasiswa yang berbeda agama, d).Dosen Al-Islam bersama Lembaga pengkajian dan pengamalan Islam tidak hanya fokus pada masalah peribadatan saja tetapi juga pada masalah sosial, e). nilai Insāniyah yang ditamkan adalah silaturahim, kebersamaan, berbaik sangka kepada sesama manusia, sikap rendah hati, tepat janji, sikap lapang dada dan toleran, sikap tolongmenolong kepada sesama manusia serta saling menghargai dan menghormati dalam perbedaan meskipun berbeda agama.

\section{Proses Internalisasi Nilai-nilai Dakwah Multikultural dalam Pembelajaran Al-Islam di Universitas Muhammadiyah Mataram}

Dari hasil penemuan peneliti bahwa proses internalisasi nilai-nilai pendidikan multikultural dalam pembelajaran Al-Islam di Universitas Muhammadiyah Mataram diwujudkan dalam bentuk kegiatan belajar mengajar mata kuliah Al-Islam di dalam kelas, namun mata kuliah Al-Islam hanya satu kali dalam seminggu sehingga proses internalisasi nilai-nilai pendidikan multikultural dalam pembelajaran Al-Islam justru peneliti temukan dalam bentuk banyak kegiatan-kegiatan internalisasi nilai di luar kelas yang lebih sering dan rutin diikuti oleh mahasiswa seperti mengikuti kultum setiap hari selesai shalat dzuhur berjamaah di masjid kampus Universitas Muhammadiyah Mataram dan banyak lagi kegiatan lainnya di luar kelas untuk 
menginternalisasikan nilai-nilai ilāhiyah dan nilai Insāniyah atau nilai-nilai pendidikan multikultural dalam pembelajaran Al-Islam di Universitas Muhammadiyah Mataram. ${ }^{9}$

\section{Kesimpulan}

Nilai-nilai dakwah multikultural dalam pembelajaran Al-Islam yang diinternalisasikan di Universitas Muhammadiyah Mataram adalah nilai Ilāhiyah dan nilai Insāniyah, nilai-nilai tersebut terwujud dan terbentuk dalam diri mahasiswa setelah melalui banyak tahap dan proses, melalui kegiatan pembelajaran Al-Islam di dalam kelas maupun di luar kelas serta melalui berbagai strategi, internalisasi tersebut diupayakan oleh dosen-dosen Al-Islam bersama Lembaga Pengkajian dan Pengamalan Islam (LP2I) Universitas Muhammadiyah Mataram.

Berdasarkan temuan dari lapangan yang paling menonjol dari nilai-nilai dakwah multikultural yang di internalisasikan dalam pembelajaran Al-Islam di dalam kelas maupun di luar kelas adalah nilai Ilāhiyah dan nilai Insāniyah, nilai Ilāhiyah ini terangkum dalam materi silabus pembelajaran Al-Islam 1 di dalam kelas dan kegiatan-kegiatan keislaman diluar kelas yang mencakup nilai iman, islam, takwa, ihsan, syukur, tawakal, dan sabar yang diinternalisasikan melalui pembelajaran di kelas dan kegiatan siraman rohani di luar kelas seperti dalam khotbah jumat, IMTAQ sabtu pagi, kultum setiap ba'da dzuhur.

Nilai Ilāhiyah tersebut ditekankan kepada mahasiswa yang multikultur homogen yaitu berbeda suku, budaya dan ormas namun semuanya beragama Islam, multikulrural homogen inilah yang mayoritas dan mendominasi di Universitas Muhammadiyah Mataram dan mencapai $90 \%$ dari jumlah mahasiswa, adapun bagi mahaiswa yang berbeda agama atau multikultural heterogen hanya berjumlah $10 \%$ dari jumlah mahasiswa dan ditekankan kepada mereka adalah nilai Insāniyah.

Nilai Insāniyah yang di internalisasikan mencakup nilai-nilai kemanusiaan, nilai kebersamaan, Silaturahim, yaitu pertalian rasa cinta kasih pada sesama manusia, semangat persaudaraan, berbaik sangka, menolong sesama manusia seperti penyaluran daging hewan kurban kepada mahasiswa non-muslim, penggalangan dana bersama untuk korban bencana, Internalisasi nilai Ilāhiyah dan nilai Insāniyah ditanamkan melalui kegiatan yang diselenggarakan oleh Lembaga Pengkajian dan Pengamalan Islam (LP2I) Universitas Muhammadiyah Mataram bersama para dosen Al-Islam melalui pembelajaran Al-Islam di dalam kelas, kegiatan-kegiatan internalisasi nilai di luar kelas, melalui banyak tahapan dan strategi serta dukungan dari berbagai pihak dan unsur pimpinan Universitas Muhammadiyah Mataram.

Proses internalisasi nilai-nilai dakwah multikultural dalam pembelajaran Al-Islam di Universitas Muhammadiyah Mataram terlaksana melalui beberapa tahapan-tahapan internalisasi yang ditanamkan oleh dosen-dosen Al-Islam beserta Lembaga Pengkajian dan Pengamalan Islam (LP2I), berdasarkan temuan peneliti dilapangan adalah: a) Tahap Pemahaman yaitu memberi pengetahuan informasi yang sebenar-benarnya mengenai nilai-nilai dakwah multikultural melalui pembelajaran Al-Islam baik formal di dalam kelas maupun kegiatan lainnya di luar kelas sehingga mahsiswa dapat memahami pentingnya sikap toleransi dan saling menghargai meskipun berasal dari latar belakang suku, budaya dan paham yang berbeda. (b) Tahap Peneladanan yaitu mengedepankan aspek perilaku dalam bentuk tindakan nyata (c) Tahap Pembiasaan yaitu menjadikan sesuatu yang belum pernah dikenal, menjadi sesuatu yang biasa dilakukan dan akhirnya menjadi terbiasa

Proses internalisasi nilai-nilai dakwah multikultural dalam pembelajaran Al-Islam di Universitas Muhammadiyah Mataram di wujudkan dalam bentuk kegiatan pembelajaran mata kuliah Al-Islam di dalam kelas maupun kegiatan internalisasi nilai di luar kelas, bentuk kegiatan- 
kegiatan internalisasi tersebut adalah: a) Pembelajaran Al-Islam di dalam kelas; b) Sholat dzhuhur berjamaah di masjid kampus Universitas muhammadiyah; Mataram dan dilanjutkan dengan KULTUM atau siramah rohani singkat; c) Serifikasi baca Al-Qur'an dengan metode Tsabita; d) Tausyiah atau siraman rohani berupa kegiatan IMTAQ rutin setiap sabtu pagi; e) Pelaksanaan Shalat Jum'at di masjid kampus Universitas Muhammadiyah Mataram.

Proses internalisasi nilai-nilai dakwah multikultural dalam pembelajaran Al-Islam di Universitas Muhammadiyah Mataram dilakukan dengan menggunkan beberapa strategi yang dilakukan dosen-dosen Al-Islam bersama Lembaga Pengkajian dan Pengamalan Islam (LP2I) Universitas Muhammadiyah Mataram, berdasarkan temuan peneliti dilapangan adalah: a) Melakukan perencanaan progam; b) Melakukan pendekatan pada mahasiswa; c) Memberikan Teladan; d) Melalui Kebijakan Pimpinan Universitas; e) Kerjasama dengan organisasi kemahasiswaan seperti Ikatan Mahasiswa Muhammadiyah (IMM).

Hasil dari internalisasi nilai-nilai dakwah multikultural dalam pembelajaran Al-Islam melalui Lembaga Pengkajian dan Pengamalan Islam (LP2I) di Universitas Muhammadiyah Mataram adalah mahasiswa dapat memahami dan mengamalkan nilai-nilai tersebut, dengan internalisasi tersebut mahasiswa memiliki karakter religious culture, hal ini terlihat dari kegiatan sehari-hari seperti pelaksanaan shalat dzhuhur berjamaah di masjid kampus Universitas Muhammadiyah Mataram, mahasiswa memiliki moralitas yang baik seperti sopan santun, saling menghormati, dan toleransi dalam perbedaan meskipun berbeda ormas dan agama namun suasana tetap damai dan rukun.

\section{DAFTAR PUSTAKA}

Ainurrofiq, Dawam. 2003. Jurnal Ilmiah: "EMOH" Sekolah: Menolak "Komersialisasi Pendidikan" dan "Kanibalisme Intelektual" menuju Pendidikan Multikultural, Yogyakarta: Inspeal Ahimsakarya Press.

Arikunto, Suharsimi. 1985. Prosedur Penelitian Suatu Pendekatan Praktek (Jakarta: Bina Aksara.

Asmani, Amal Ma'mur. 2011, Tuntunan Lengkap Metodelogi Praktis Penelitian Pendidikan. Jogjakarta : Diva Press, cetakan II

Azanuddin, 2010.Tesis: Pembelajaran PAI Berbasis Multikultural Dalam Mengembangkan Budaya Toleransi Beragama di SMAN 1 Amlapura, Malang: Universitas Islam Maulana Malik Ibrahim Prodi Manajemen Pendidikan Islam.

Bungin, Burhan 2007. Metode Penelitian Kualitatif Jakarta: PT. Raja Gravindo Persada

Chaplin, 1993.Kamus Lengkap Psikologi (Jakarta: PT Raja Grafindo Persada.

DEPDIKBUD, 1989.Kamus Besar Bahasa Indonesia , Jakarta: Balai Pustaka.

Drikarya, 1980.Tentang Pendidikan Jakarta: Kanisius,

H.A.R.Tilaar, 2000.Pendidikan, Kebudayaan, dan Masyarakat Madani Indonesia: Strategi Reformasi Pendidikan Indonesia, Bandung: Rosdakarya

Hafiduin, Didin dan Hendri Tanjung. 2003. Manajemen syari'at dalam peraktek Jakarta: Gema Insani

Hakiemah, Ainun, 2007. Tesis: Nilai-nilai dan Konsep Pendidikan Multikultural dalam Pendidikan Islam, Yogyakarta: Universitas Islam Negeri Sunan Kalijaga.

Hasan, Iqbal. 2004. Analisis Data Penelitian Dengan Statistik. Jakarta: Bumi Aksara.

Hasan, M. Iqbal 2002. Pokok-Pokok Metodologi Penelitian dan Aplikasinya (Jakarta: Penerbit Ghlmia Indonesia.

Idris, Zahara, 1987. Dasar-Dasar Kependidikan Padang: Angkasa Raya 
Istighfaroh, 2012.Jurnal Pendidikan : Journal of Educational Social Studies jurnal, Konsep Multikultural dalam Kehidupan di Pondok Pesantren Al-Asror, Semarang: Universitas Negeri Semarang, Jurnal edisi 1 (2).

Lembaga Pengkajian dan Pengamalan Islam Universitas Muhammadiyah Mataram, 2013.Pedoman Buku Ajar Al-Islam, Mataram: LP2I,

Margono, 2005.Metodologi Penelitian Pendidikan Jakarta: Rineka Cipta

Maslikhah, 2007.Quo Vadis Pendidikan Multikultural: Reconstruksi Sistem Pendidikan berbasis Kebangsaan, Surabaya: JP Books.

Moleong, Lexy J. 2005. Metodologi Penelitian Kualitatif Edisi Revisi, Bandung: PT. Remaja Rosdakarya.

Muhaimin, 1996.Srategi Belajar Mengajar. Surabaya: Citra Media.

Mundzier Suparta, 2008. Islamic Multicultural Education: Sebuah Refleksi Atas Pendidikan Agama Islam Di Indonesia, Jakarta: Al Ghazali Center.

Nabawi, Hadari 2005. Metode Penelitian Bidang Sosial Yogyakarta: Gajah Mada Press,

Nashori, Fuad dan Rachmy Diana Mucharam, 2002. Mengembangkan Kreativitas Dalam Perspektif Psikologi Islam, Yogyakarta: Menara Kudus,.

Nasution, 1998.Metode Penelitian Naturalistik Kualitatif. Bandung: Taristo

Sugiyono, 2010.Metode Penelitian Pendidikan Pendekata Kuantitatif, Kualitatif, dan R\&D . Bandung: Alfabeta

Sukmadinata, Nana Syaodih 2007.Metode Penelitian Pendidikan, Bandung: Remaja Rosdakarya.

Tim Penyusun UURI.2006. Undang-Undang Republik Indonesia Nomor 14 Tahun 2005 Tentang Guru dan Dosen, Bandung: Citra Umbara.

Tobroni, Pendidikan Karakter Dalam Perspektif Islam(http://tobroni.staff.umm.ac.id. diakses 26 September 2014).

Yaqin, M. Ainul, 2005 Pendidikan Multikultural: Cross-Cultural Understanding untuk Demokrasi dan keadilan, Yogyakarta: Pilar Media. 